\title{
Influence of a lifestyle intervention in preschool children on physiological and psychological parameters (Ballabeina): study design of a cluster randomized controlled trial Iris Niederer*1, Susi Kriemler ${ }^{1}$, Lukas Zahner ${ }^{1}$, Flavia Bürgi ${ }^{1}$, Vincent Ebenegger ${ }^{2}$, Tim Hartmann ${ }^{1}$, Ursina Meyer ${ }^{1}$, Christian Schindler ${ }^{3}$, Andreas Nydegger ${ }^{4}$, Pedro Marques-Vidal ${ }^{5}$ and Jardena J Puder ${ }^{6}$
}

\begin{abstract}
Address: ${ }^{1}$ Institute of Exercise and Health Sciences, University of Basel, Basel, Switzerland, ${ }^{2}$ Institute of Sports Sciences and Physical Education, University of Lausanne, Lausanne, Switzerland, ${ }^{3}$ Institute of Social and Preventive Medicine, University of Basel, Basel, Switzerland, ${ }^{4}$ Department of Paediatric Gastroenterology and Nutrition, Centre Hospitalier Universitaire Vaudois, University of Lausanne, Lausanne, Switzerland, 5 Institute of Social and Preventive Medicine, Centre Hospitalier Universitaire Vaudois, University of Lausanne, Lausanne, Switzerland and ${ }^{6}$ Service of Endocrinology, Diabetes and Metabolism, Centre Hospitalier Universitaire Vaudois, University of Lausanne, Lausanne, Switzerland

Email: Iris Niederer* - iris.niederer@unibas.ch; Susi Kriemler - susi.kriemler@unibas.ch; Lukas Zahner - lukas.zahner@unibas.ch; Flavia Bürgi - flavia.buergi@unibas.ch; Vincent Ebenegger - vincent.ebenegger@unil.ch; Tim Hartmann - tim.hartmann@unibas.ch; Ursina Meyer - ursina.meyer@unibas.ch; Christian Schindler - christian.schindler@unibas.ch; Andreas Nydegger - andreas.nydegger@chuv.ch; Pedro Marques-Vidal - pedro-manuel.marques-vidal@chuv.ch; Jardena J Puder - jardena.puder@chuv.ch

* Corresponding author
\end{abstract}

Published: 3I March 2009

BMC Public Health 2009, 9:94 doi:10.1 I86/147I-2458-9-94
Received: 4 March 2009

Accepted: 3I March 2009

This article is available from: http://www.biomedcentral.com/I47I-2458/9/94

(C) 2009 Niederer et al; licensee BioMed Central Ltd.

This is an Open Access article distributed under the terms of the Creative Commons Attribution License (http://creativecommons.org/licenses/by/2.0), which permits unrestricted use, distribution, and reproduction in any medium, provided the original work is properly cited.

\begin{abstract}
Background: Childhood obesity and physical inactivity are increasing dramatically worldwide. Children of low socioeconomic status and/or children of migrant background are especially at risk. In general, the overall effectiveness of school-based programs on health-related outcomes has been disappointing. A special gap exists for younger children and in high risk groups.
\end{abstract}

Methods/Design: This paper describes the rationale, design, curriculum, and evaluation of a multicenter preschool randomized intervention study conducted in areas with a high migrant population in two out of 26 Swiss cantons. Twenty preschool classes in the German (canton St. Gallen) and another 20 in the French (canton Vaud) part of Switzerland were separately selected and randomized to an intervention and a control arm by the use of opaque envelopes. The multidisciplinary lifestyle intervention aimed to increase physical activity and sleep duration, to reinforce healthy nutrition and eating behaviour, and to reduce media use. According to the ecological model, it included children, their parents and the teachers. The regular teachers performed the majority of the intervention and were supported by a local health promoter. The intervention included physical activity lessons, adaptation of the built infrastructure; promotion of regional extracurricular physical activity; playful lessons about nutrition, media use and sleep, funny homework cards and information materials for teachers and parents. It lasted one school year. Baseline and post-intervention evaluations were performed in both arms. Primary outcome measures included BMI and aerobic fitness ( $20 \mathrm{~m}$ shuttle run test). Secondary outcomes included total (skinfolds, bioelectrical impedance) and central (waist circumference) body fat, motor abilities (obstacle course, static and dynamic balance), physical activity and sleep duration (accelerometry and questionnaires), nutritional behaviour and food intake, media use, quality of life and signs of 
hyperactivity (questionnaires), attention and spatial working memory ability (two validated tests). Researchers were blinded to group allocation.

Discussion: The purpose of this paper is to outline the design of a school-based multicenter cluster randomized, controlled trial aiming to reduce body mass index and to increase aerobic fitness in preschool children in culturally different parts of Switzerland with a high migrant population.

Trial Registration: Trial Registration: clinicaltrials.gov NCT00674544

\section{Background}

Obesity is considered to be a global epidemic by the World Health Organization [1]. The marked increase in childhood obesity is alarming and already present in preschool children reaching $26 \%$ in 2 - to 5 -year old children and to $37 \%$ in 6- to 11 -year old children [2]. In Switzerland there is a prevalence of overweight and obesity of around $20 \%$ and $23 \%$ in 6- to 12 -year old boys and girls [3]. The prevalence of overweight/obesity and of physical inactivity is especially increased in children of low socioeconomic status (SES) [4] and/or children of migrant background $[5,6]$.

Obese children are at increased risk to become obese adults $[7,8]$ and this tracking becomes stronger the closer the child gets to adult status [9]. Yet, overweight preschool children have an over fivefold risk to be overweight at age twelve years compared with normal weight preschoolers [8]. Childhood obesity is already associated with cardiovascular disease risk factors [10-13] as well as other complications $[7,8]$ and is an independent predictor of coronary heart disease in adulthood [14].

The main environmental causes attributed to the enormous increase in body fatness in the last few decades are an increase in energy intake through food and a decrease in energy expenditure through a decrease in physical activity (PA) and/or an increase in sedentary behaviour [15]. One of the most important contributors to sedentary behaviour is media use (TV, PC, game use) [16] which is also related to energy intake [16]. Another postulated factor associated with obesity and insulin resistance is a lack of sleep [17]. Social, cultural and economic factors also influence energy balance.

In the last years, cross-sectional and longitudinal data have shown that the increased intake of foods with high fat or sugar content [18], high energy snacks, sweets and sugar-added beverages is associated with increasing BMI [18-20]. In addition, over the last 20 years, aerobic fitness has decreased by around $8 \%$ in children from developed countries [21]. In contrast to aerobic fitness, there are no population-level objective data on temporal changes in total PA. However, some data indicate that children have become less physically active or less engaged in sports par- ticipation in the last years [22,23]. Nowadays, 3- to 5-year old children monitored with accelerometers spent around $80 \%$ of their time in activities of $<1100$ counts/min [24], which is considered to be sedentary behaviour or at most light PA [25]. In children, physical inactivity and reduced aerobic fitness are associated with increasing prevalence of cardiovascular risk factors [26-28] even independently of weight status $[28,29]$.

As the great majority of obesity treatment studies show a lack of selected and longstanding effectiveness [30], primary prevention is absolutely essential. But short- and long-term studies in recent reviews show only small or no positive effects in BMI, SF and/or PA [31-34]. Implementing successful studies or projects is even more difficult in children from families of less advantaged SES and/or migrant background [34,35]. Although the period between the ages four and seven (the timing and the magnitude of the so called obesity rebound) has been suggested as a crucial time for development of overweight and obesity in children, there is a lack of studies in younger children [34]. For these reasons, we developed a study to assess the effect of a multidisciplinary lifestyle intervention on BMI and aerobic fitness by focusing on a young age group (preschoolers) and on children of migrant background (Ballabeina - Kinder im Gleichgewicht/enfants en équilibre). Ballabeina is RhaetoRomanic and means swing, teeter-totter, seesaw. This name of the study stands for a life in drive but also in balance.

\section{Theoretical model}

Causes for overweight and obesity are multifaceted and prevention is difficult and complex. In the last years, social models of health promotion have been increasingly used to study complex interactions [36,37], as simple interventions are unlikely to work on their own and the development of effective preventive interventions requires strategies that affect multiple settings simultaneously [38]. Ballabeina is based on the social ecological model [36] (figure 1), that includes concentric rings that influence lifestyle patterns. The "psychobiologic core" of the model represents the genetic, physiologic, and socio-cultural forces that shape ones identity (individual child). This core is surrounded by the microsystem, the immedi- 


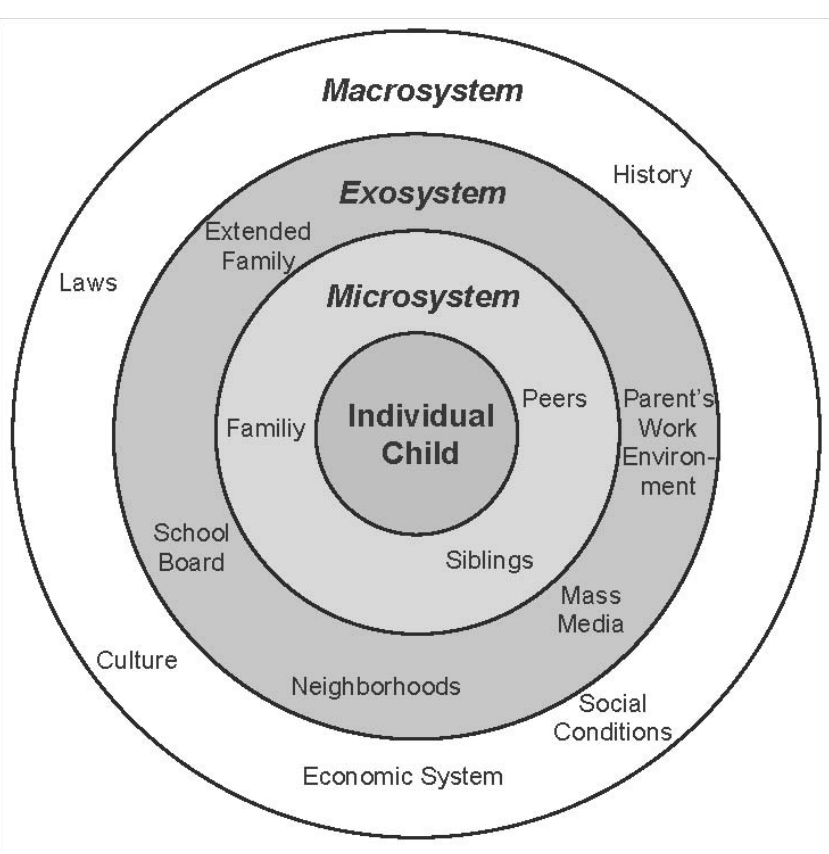

Figure I

Ecological Model. Bronfenbrenner's Ecological Model describing the environmental influences on a child, with permission from [39].

ate environments with which a child interacts (parents, siblings, teachers, peers, etc.). The exosystem includes environments with which the child doesn't usually directly interact, but that can still affect the child (school boards, etc.). The macrosystem includes the broad societal settings under which the other cycles function (culture, history, social norms, economic system, etc.). For preschooler, the two main influence factors are the family and the teachers [39]. That's why the main intervention targets included these settings. The program promotes a healthy lifestyle by positively influencing personal, behavioral, and environmental factors. On the one side the intervention program transferred knowledge about adequate PA, nutrition and healthy food selection, reduced media use and proper sleep. On the other side the intervention also seeked to change the behavior of the child by increasing skills like motor abilities and augmenting daily PA. In addition the children and parents learned in a practical way strategies to change their nutritional behavior according to five nutrition messages (see below). The teachers achieved competencies by implementing PA and nutrition lessons in the preschool. On the environmental level, the built infrastructure (in- and outdoor in preschool) was adapted to enhance the child's natural behaviour to move and to explore. Participation of the children in extracurricular sport activities (club, etc.) in their neighbourhoods was promoted. The Ballabeina team also collaborated with the school boards, the building authorities and the school health services.

\section{Methods/Design Study objectives}

The aim of the study was to evaluate the effects of a multidisciplinary multilevel lifestyle intervention in preschool children (aged 4- to 6-years) during one school-year in a multicenter cluster randomized controlled trial. The study included 40 randomly selected preschool classes and was conducted in the French (canton Vaud, VD) and in the German (canton St. Gallen, SG) part of Switzerland, focusing on areas with a high prevalence of migrant children.

\section{Main outcomes}

Primary outcomes:

- BMI

- Aerobic fitness (20 m shuttle run)

Secondary outcomes:

- Total (sum of four SF, bioelectrical impedance) and central (waist circumference) body fatness

- Other motor abilities (obstacle course, balance platform, balance beam)

- PA and sleep duration (accelerometry and questionnaires), media use, nutritional behaviour and food intake of the child and the family (all questionnaires)

- General health (child and family), health-related quality of life, presence of hyperactivity (all questionnaires)

- Cognition tests (testing attention and spatial working memory ability)

Null-hypothesis: Potential differences in the primary outcomes between the INT and the CON groups at the end of the intervention will be entirely due to chance.

\section{Study Design}

Figure 2 shows a flow diagram of the recruited population. It was performed in two (SG \& VD) out of 26 Swiss cantons. The German (SG) and the French (VD) parts of Switzerland represent two culturally distinct regions with different school and preschool systems. Classes from SG and VD were therefore separately selected and randomized after agreement of the school directors and the school health services of both cantons. The city of St. Gallen and the Lausanne area were chosen due to a high prevalence (i.e. at least $40 \%$ ) of children of migrant background. Migrant background was defined as at least one parent born out of Switzerland. The prevalence of $40 \%$ was chosen as the school board estimated that in 
large adjacent areas with a high prevalence of a migrant population, $40-70 \%$ of children were of migrant background. For the selection and randomization opaque envelopes were used. For practical reasons, and to reduce an effect of contamination, preschool classes integrated in the same school building were randomized into the same group.

For all children an informed consent from a parent or a legal representative was necessary in order to participate in the study. Of the 727 children visited the chosen preschools, consent was obtained from parents/legal representatives for 655 (343 in the INT and 312 in the CON, participation rate: $90.1 \%)$.

The study was approved by the cantonal ethical committees of St. Gallen and Vaud.

\section{Need assessment, preplanning and pilot studies}

In a first step a broad state of the art of health promoting projects in Swiss preschools [40-44] and a requirement analysis (knowledge, existing offers and barriers) was done. Teachers, health professionals and migrant experts were interviewed and asked to respond to a structured questionnaire. We also interviewed parents of migrant background with special emphasis on nutrition and PA behaviours (Jörg R, unpublished license of diploma, University of Basel). We performed qualitative interviews and designed and distributed questionnaires about their health perception, individual needs and attitudes towards offers in five preschool classes. Physical education classes were visited and analyzed. Based on this analysis, we determined content and transmission of information, as well as the extracurricular offers. We then performed different pilot studies (table 1) before the beginning of the main intervention.

\section{Intervention}

The intervention was developed with input from exercise physiologists, preschool and primary school teachers, paediatricians, dieticians, psychologists and various stakeholders including experts for migrant families). The intervention focused on four topics: PA, nutrition, media use and sleep duration and was primarily applied at the level of the teachers, children and parents. All INT classes proceeded according to the same curriculum i.e. workshops, lessons, home activities, offers of extra-curricular activities, adaptation of the built infrastructure. The teachers were coached by trained health promoters (HP). These were physical education teachers who were further trained by a dietician and a physician. Theses HP intervened on the level of the teachers, the children, the parents and the local community. The CON group continued to follow their usual school curriculum which included one $45 \mathrm{~min}$ physical education lesson taught by the classroom teachers and one 45 min rhythmic lesson (given by a rhythmic specialist) for the French part of the study. Children were blinded to the existence of INT classes. The teachers and the parents, however, knew about the intervention arm. Participants, parents and school personnel, including classroom teachers, were informed that the intervention would promote their children's health, but were unaware of the main objectives.

\section{Teachers}

Prior to the intervention, the teachers took part in two afternoon workshops on the four topics (PA, nutrition, media use and sleep). In these workshops the teachers learned how to work with the lessons, the homework cards, the new PA infrastructure material. During the study, regular informal exchanges between the teachers and the HP took place and two formal meetings were organized.

\section{Children}

PA lessons

PA lessons were given four times a week including $40 \mathrm{~min}$ lessons and $5 \mathrm{~min}$ cool down. In the beginning, one of the four lessons was given by the HP with the regular classroom teachers attending these lessons. After four months of intervention, the HP reduced their contribution to twice a month while the remaining lessons were taken over by the preschool teachers. All PA lessons were prepared by an exercise physiologist. The lessons took place in or around the preschool and once a week in the gym. Training of coordination and endurance was performed as described in figure 3. Additional sports equipment for the lessons such as balls, skipping ropes was offered and organized. Adherence to the PA lessons was assessed by regular classroom teachers.

\section{Nutrition, media use and sleep lessons}

The intervention on healthy balanced nutrition included weekly $45 \mathrm{~min}$ nutrition lessons, where the children learned balanced nutrition and healthy nutritional behaviour in a playful way. These lessons were developed and prepared by a dietician. The lessons were based on five messages i.e. "drink water", "eat fruit and vegetables", "eat regularly", "make clever choices", "turn your screen off when you eat" [42] that were transmitted in the form of a nutrition disk, developed in collaboration with the Swiss Society for Nutrition [45]. Each message was taught during a two-weeks period and was presented in two cycles over the year. Each message was described on a funny card which was taken at home with a task to implement the message at home (see below). During two additional weeks, lessons about sleep were implemented.

\section{Infrastructural changes}

The infrastructures of the preschool were adapted, in coordination with the building department to ensure the insurance guidelines for prevention of accidents. 


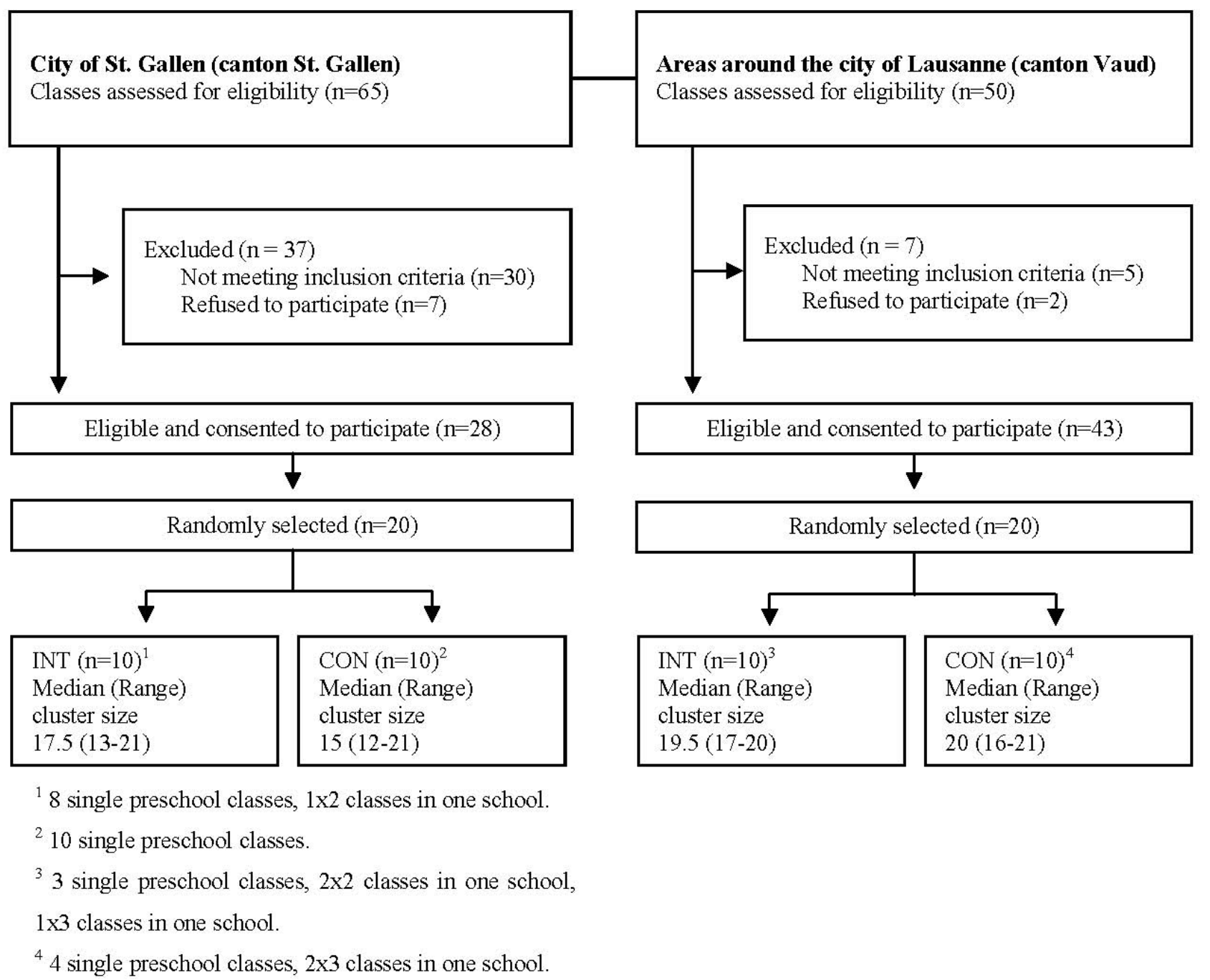

Figure 2

Participants flow chart.

\section{Extracurricular activities}

This included an additional weekly PA lesson (e.g. clubs). Where there was no offer of inexpensive all-round weekly PA lessons a weekly extracurricular lesson from a new national PA program [46] was offered.

\section{Children and parents}

\section{$P A$ and nutrition home activities}

Sixteen PA and five nutrition cards were developed by professional PA teachers/nutritionists in collaboration with Health Promotion Switzerland [43]. The children got every other week a new PA or a nutrition activity card at home. These cards include specific PA tasks to be done at home. Some of these activities focused on a team work, which should promote the integration of other family members. A text on the backside of the card included simple information and practical hints to the parents. A CD with specific music for most PA cards was created to increase pleasure and define the minimal time the activity should be performed.

\section{Events}

Toward the end of the intervention, a morning event was organized, where children and parents participated together in a fun program while implementing the main messages of the study.

\section{Parents}

\section{Information evenings}

The HP organized two information evenings in each preschool. During the first information evening the HP informed about the study, the intervention, the testing and the informed consent. This information evening was performed also for the CON classes. On the second infor- 
Table I: Overview of the different pilot studies:

Pilot studies evaluating the intervention (PI) Pilot studies evaluating the measurements (PM)

I I/2006: Testing of 10 PA home activity cards in 5 preschool classes for 4 weeks.

Evaluation by teachers and parents (questionnaires).

5/2007: Testing of 2 further PA and 2 nutrition home activity cards in 4 preschool classes. Evaluation by teachers and parents (questionnaires).

I I/2007: Testing of daily PA and weekly nutritional lessons with their home activity cards during 3 weeks in I preschool class. Evaluation by teachers and parents (questionnaires).
Feasibility and selection of tests

1 I/2007: Evaluation of 10 motor ability tests in one preschool class and selection of 4 of them by a team of sports scientists. Evaluation of the anthropometric measurements and the cognitive tests.

Feasibility and reliability of tests

4/2008: Evaluation of the 4 motor ability tests in 2 preschool classes. Test-retest reliability of the balance platform test (static balance) and the anthropometric measurements.

Reliability of motor ability tests 6/2008: Test-retest reliability of the "obstacle course" test (combined motor ability) and the balance beam test (dynamic balance) I preschool class.

mation evening, the HP presented the nutrition disk, informed about the five nutrition and media use messages and discussed possibilities and barriers of implementation. A third information evening performed by a dietician discussed the possibility of healthy nutrition that is cheap, tasty and can be easily and rapidly prepared.

\section{Information booklet}

In a short booklet, parents got informed about: (1) details of the intervention (2) practical hints to increase PA for children and for adults (3) existing PA offers for preschooler in the neighbourhood (4) the material, the children need at home for the home activities (5) the nutrition disc and (6) recommendations for a healthy mid-morning snack.

With the second information event the parents received the nutrition disc (offered in ten languages) and two other

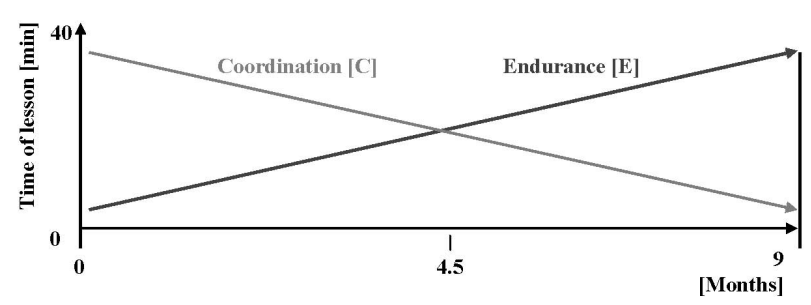

Figure 3

Model for the physical lessons. The physical activity lessons focused on coordination and endurance, but their distribution within one 40 min lesson changed over the period of the study. booklets about cooking and eating ("Gemeinsam Kochen und Essen", Cleven-Becker-Stiftung, 2008) and about PA in daily life ("Bewegung ist Leben", Bundesamt für Sport BASPO, 2008), offered in eight languages.

\section{Measurements}

Measurements at baseline and at the end of the intervention were accomplished during a time period of five weeks (beginning both times in SG). Table 2 gives an overview about all measurements taken. The measurements were collected in three teams: anthropometry/concentration/ memory (tested in the preschool class), motor abilities (tested in the gym) and PA (accelerometry). These teams worked parallel in different classes. With few exceptions the local teams did not change between the two testing periods. The main investigators for SG and VD were trained together to minimize inter-observer variability. Research assistants were blinded to group allocation. If a child was sick, BMI was measured few days later and questionnaires were distributed.

\section{Anthropometry and body composition}

Standing height was determined and body weight was measured using an electronic scale (Seca, Basel, Switzerland; accuracy $0.05 \mathrm{~g}$ ). Waist (midway between the iliac crest and the lowest border of the rib cage) and hip circumference (at the largest circumference) were measured by a flexible tape. SF thickness was measured in triplicate to the nearest $0.5 \mathrm{~mm}$ with Harpenden calipers (HSK-BI, British Indicators, UK) calibrated to exert a pressure of 10 $\mathrm{g} / \mathrm{cm}^{2}$ to the skin. Four sites (triceps, biceps, subscapular and suprailiac) were measured based on standard proce- 
dures [47]. The same four investigators took all measurements. Percent body fat was calculated according to the formulas of Slaughter, Deurenberg and Dezenberg [48$50]$ validated in preschool children $[51,52]$. The calculation of \% body fat with this method has a prediction error of $3-5 \%[48,49]$. The intra- and interobserver correlations in the pilot study $(\mathrm{n}=21)$ using Spearman rank correlation analyses were $r=0.95(\mathrm{p}<0.001)$ and $\mathrm{r}=0.90(\mathrm{p}<$ $0.001)$, respectively for waist circumference and $\mathrm{r}=0.98$ $(\mathrm{p}=0.001)$ and $\mathrm{r}=0.96(\mathrm{p}=0.001)$, respectively for the sum of four SF. Bioelectrical impedance was measured by a 4-polar single frequency device (RJL Systems, Model 101A; Detroit, MI, USA). The unit was calibrated prior to each testing day using a $500 \mathrm{ohm}$ resistor provided by the company. Measurements were taken based on standard procedure[53]. If the distance from the proximal to the distal electrode was less than $5 \mathrm{~cm}$ in small children, the proximal electrode was located more proximal until the distance of $5 \mathrm{~cm}$ was attained. Percent body fat was calculated based on validated formulas $[52,54,55]$. The coefficient of variation between different bioelectrical impedance analysis measurements was less than $1.5 \%$ and for the calculation of fat-free mass it was 5.8\% [52].

\section{Motor abilities}

Shuttle run test

The maximal multistage $20 \mathrm{~m}$ shuttle run test (20-MST) was used to assess aerobic fitness [56]. The test measures aerobic capacity by running forth and back for $20 \mathrm{~m}$ with an initial running speed of $8.0 \mathrm{~km} / \mathrm{h}$ and a progressive 0.5 $\mathrm{km} / \mathrm{h}$ increase of the running speed every minute that is indicated by a sound. The maximal performance was determined when the child was twice in series more than $3 \mathrm{~m}$ behind the given time or the child decided itself to stop because of exhaustion. The 20-MST has been found to be reliable (test-retest $r=0.73-0.93$ ) [56-58], a valid measure of maximum oxygen consumption as measured by treadmill testing $(\mathrm{r}=0.69-0.87)$ [57-61], and sensitive to changes in 6- to 16-year old children [61]. Some formal adoptions were made due to the very young age of the children by marking tracks on the floor to prevent the children from running curves and by an adult running with the children to provide the adequate pace.

\section{Obstacle course}

This test of overall fitness includes running $1 \mathrm{~m}$ from a marking cone to a transversally positioned bench, jumping over the bench ( $36 \mathrm{~cm}$ high, $28 \mathrm{~cm}$ wide), underpass this bench and running back to the marking cone three times in a row as fast as possible. Time was measured in seconds. This test was described by Vogt (1978) [62] and Kunz (1993) [63] as an ideal test for 3- to 6-year old children to test the overall fitness. The bench was constructed according to the German DIN 7909 standard except for the stabilizing bar, which was left out. Each child had two attempts and the faster one was used. Tests were considered invalid according to predefined criteria, i.e. if the performance was obviously submaximal, or the child did a mistake. The intra- and interobserver correlations in the pilot study $(\mathrm{n}=14)$ using Spearman rank correlation analyses were $r=0.99(p<0.01)$ and $r=0.82(p<0.01)$, respectively. Less than $10 \%$ of the children had one invalid attempt and none had two invalid attempts.

\section{Balance platform}

Static postural control was measured in accordance to a standardized protocol [64] on a balance platform (GKS $1000^{\circledR}$, IMM, Mittweida, Germany). The balance platform consisted of four sensors measuring displacements of the center of pressure (COP) in medio-lateral and anteriorposterior direction. Data acquisition was monitored (40 $\mathrm{Hz}$ ) for $25 \mathrm{sec}$ [64]. A balance-pad (Airex balance Pad, Airex, Aalen-Ebnat, Germany) was put on the balance platform, increasing the difficulty of the test. Postural sway was collected measuring the displacement of the COP. The smallest total length of two trial was used for further analysis. For experimental testing, children were asked to stand barefoot, with a $2 \mathrm{~cm}$ distance between

Table 2: Overview of the measurements:

\begin{tabular}{|c|c|}
\hline Anthropometry and body composition & PA, nutritional intake and behaviour, media use, sleep duration \\
\hline Height & Accelerometers, questionnaires* \\
\hline Weight & Food frequency questionnaire* \\
\hline \multicolumn{2}{|l|}{ Waist and hip circumference } \\
\hline $\begin{array}{l}\text { Skinfold thickness (triceps, biceps, subscapular, } \\
\text { suprailiacal) }\end{array}$ & $\begin{array}{l}\text { Psychosocial health } \\
\text { General health of the child and the family* }\end{array}$ \\
\hline Bioelectrical impedance (4-Polar) & $\begin{array}{l}\text { Health-related quality of life (HRQOL)* } \\
\text { Signs of Hyperactivity (SDQ)* }\end{array}$ \\
\hline \multicolumn{2}{|l|}{ Motor ability } \\
\hline Shuttle run test (aerobic fitness) & Cognition tests \\
\hline Balance platform (static balance) & Attention (KHV-VK) \\
\hline Balance beam (dynamic balance) & Spatial working memory ability (IDS) \\
\hline Obstacle course (combination) & \\
\hline
\end{tabular}

* evaluated by a total of two questionnaires (one for lifestyle parameters, general and psychosocial health, one food frequency questionnaire) 
Table 3: Overview of the questionnaires:

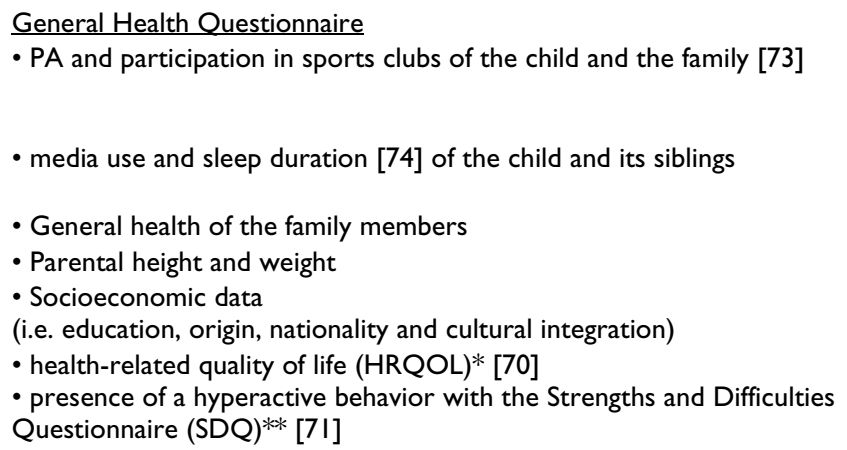

* HRQOL was measured by the German version of the PedsQL 4.0TM (Pediatric Quality of Life Inventory) Generic Core Scales (U.S. Copyright Registration No. TXu 856-10I) with a parent proxy-report, containing four scales (Physical, Emotional, Social, School) and 23 items. The psychometric properties of the PedsQL 4.0TM justify application in a healthy child population [70]. ** The presence of hyperactive behaviour was evaluated with the Strengths and Difficulties Questionnaire (SDQ) [7I]. The parent proxy-form comprised the hyperactivity/inattention scale consisting of five items. Validity has been demonstrated in healthy children and adolescents [72].

both heels and feet placed in a $30^{\circ}$ angle on the balancepad, where coloured foot prints were placed. Hands were placed on the hips. After a test-stand for five seconds and a break while children descended from the force plate, the two trials were collected. The intraobserver test-retest correlation for the total length between the two attempts in the pilot study $(\mathrm{n}=40)$ using Spearman rank correlation analyses was $r=0.73(p<0.0001)$.

\section{Balance beam}

According to Keogh (1965) balance beams are a suitable tool for testing dynamic balance in children [65]. In pilot testing we observed that balancing backwards was too difficult for children aged 4- to 6-years but balancing forward on a $3 \mathrm{~cm}$ wide balance beam was feasible and discriminated between children with high and low motor skills. We therefore included balancing barefoot forward on a 3 $\mathrm{m}$ long and $3 \mathrm{~cm}$ wide balance beam. The number of successful steps on the beam were counted until the child's foot touched the floor. Children performed three trials. The mean of the best two trials was calculated and used for further analyses. The intra- and interobserver correlation between the two better attempts in a pilot study $(\mathrm{n}=15)$ using Spearman rank correlation analyses were $\mathrm{r}=0.84(\mathrm{p}$ $<0.01)$ and $\mathrm{r}=0.97(\mathrm{p}<0.01)$, respectively.

\section{Physical activity}

PA was assessed by an accelerometer (MTI/CSA 7164, Actigraph, Shalimar, FL, USA). The accelerometers were constantly worn around the hip over five days at baseline and at the end of the intervention (both summertime) in the INT and in the CON group. The sampling epoch was set at $15 \mathrm{sec}$. This instrument has been shown to be valid across different activities in 3- to 5-year old children with a Pearson correlation coefficient between $\mathrm{VO}_{2}(\mathrm{ml} / \mathrm{kg}$ per $\mathrm{min}$ ) and Actigraph counts/15 sec of $\mathrm{r}=0.82$ [66].
Food frequency questionnaire (adapted from [67-69])

- Nutritional behavior

(i.e. if and where (i.e. home, day care) the meals were eaten, eating while

watching television, eating alone)

- Intake of 15 different categories of food during the last 4 weeks (subdivided into nutriments)

\section{Questionnaires}

Table 3 gives an overview of the two used questionnaires [67-74]. The reliability of a semi-qualitative food frequency questionnaire was tested in three classes assessing nutritional behaviour and food intake of preschool children of predominantly migrant background (Ebenegger, V. manuscript in preparation). Items were chosen from different food frequency questionnaires [67-69] adapted to the Swiss situation and the age group. This food frequency questionnaire was also filled in for each sibling aged two years or older.

\section{Cognition tests}

To measure attention ability, the Konzentrations-Handlungsverfahren für Vorschulkinder (KHV-VK) [75] was applied. Test material consists of 44 cards with familiar pictures, which had to be sorted into four different boxes. Sorting time and error quote allowed quantitative and qualitative statements on attention. The test has been validated in a preschool population and age specific norms are available. Test-retest reliability was $r=0.88$ [75].

Spatial working memory ability was measured by a subtest taken from the Intelligence and Development Scales (IDS) [76]. Thereby geometrical forms had to be memorized and identified. Significant correlations to related measures confirmed construct validity (i.e. HAWIK-IV Working memory scale: $r=0.52$ ) and the testretest reliability was $\mathrm{r}=0.48[77,78]$.

\section{Evaluation}

All evaluation measures were developed as defined in the CONSORT guidelines [79]. We will evaluate the intervention with regard to primary and secondary outcome measures. We will also perform a process evaluation to assess the appreciation the feasibility and the subjective effec- 
tiveness of the program by teachers (questionnaires and semi-qualitative interviews) and parents (questionnaires).

\section{Data analysis}

Baseline comparability of INT and CON schools will be assessed using descriptive statistics and two sample $t$ test for continuous and $\chi^{2}$ test for categorical variables. If necessary, variables will be logarithmically transformed before analyses. As a primary prevention program, the intervention was designed to target the entire sample. Effects are expected and intended to occur throughout the entire distribution of adiposity and aerobic fitness in the sample - not just around a defined threshold. Thus, for purposes of establishing the efficacy of this intervention, it is most appropriate to compare the full distributions of BMI and aerobic fitness between INT and CON groups. Therefore, to test the primary hypotheses, accounting for the design with classes as the unit of randomization, mixed linear models will be used, with change in BMI and aerobic fitness as the dependent variable, study arm as the factor of interest and age, sex, language region (German vs. French part of Switzerland) and baseline BMI or aerobic fitness, respectively, as covariates. The same analytic approach will also be used for all secondary outcome variables. Potential interactions of intervention with sex or age will be tested for each outcome. Data will be analyzed according to intention to treat.

With an average class size of 18 , we assumed that 13 children per class would participate in both shuttle run-tests (due to non-participation, attrition, moving, sickness on the testing day). A total number of 40 classes would then provide enough power to detect a true intervention effect of half an inter-subject standard deviation at the usual significance level of 0.05 with a probability of 0.9 , provided that the standard deviation of the random class effect does not exceed $25 \%$ of the inter-subject standard deviation (i.e., corresponding to an intra-class correlation of about $0.06)$.

The following subgroups will be also investigated: Normal weight and overweight/obese children, children with low baseline fitness, children with migrant background and Swiss children, children of low socioeconomic background.

\section{Discussion}

We achieve to develop a concise and appropriate protocol for the development and implementation of a multilevel lifestyle intervention aiming to prevent weight gain and to increase aerobic fitness in a high-risk preschool population with a high percentage of migrant background. We believe that the inclusion of stakeholders such as teachers, parents and school directors from the very beginning, the extended preplanning inlcuding testing and evaluation of the intervention material and the theory-driven multilevel approach will improve the likelihood of a successful intervention.

The purpose of this paper was to outline the design of a multicomponent multilevel school-based multicenter cluster-randomized, lifestyle intervention trial aiming to reduce BMI and to increase aerobic fitness in 4- to 6-year old preschool children in culturally different parts of Switzerland with a high prevalence of migrant children. We aim to offer information and a solid base for a further adaption and larger implementation of prevention programs focusing on preschool children that are adapted to children of low SES and migrant background. Results of the intervention will be available in 2010 .

\section{Competing interests}

The authors declare that they have no competing interests.

\section{Authors' contributions}

JJP, SK and LZ designed the study. JJP was the principal investigator and is guarantor. JJP, SK, IN, FB, VE, AN, TH and PM established the methods and questionnaires. IN, $\mathrm{FB}, \mathrm{VE}$ and JP were the main coordinators of the study. IN, FB, VE, UM, AN, PM and JJP conducted the study. CS and PM gave statistical and epidemiological support. IN wrote the article under the assistance of JJP and got additional help from SK and PM. JJP obtained the funding, with the assistance of SK and LZ. All authors provided comments on the drafts and have read and approved the final version.

\section{Acknowledgements}

Ballabeina was principally supported by the Swiss National Science Foundation (Grant \# 3200B0-I I 6837) and Health Promotion Switzerland (Project \# 2104). Additional funding was obtained from a research award for Interdisciplinary Research from the University of Lausanne, a Takeda research award, the Wyeth Foundation for the Health of children and adolescents, the Freie Akademische Gesellschaft and an educational grant from Nestlé.

We thank all the children, their parents and the teachers for their superb participation and the school directors and the school health services for their invaluable help in the study. A special thank goes to Dr. Ursula Kälin, Beatrice Liechti and Hélène Schoeb for the professional collaboration and to Claudia Rey and Antoine Bovin for their efforts and their excellent work with the children.

\section{References}

I. Obesity: preventing and managing the global epidemic. Report of a WHO consultation. World Health Organ Tech Rep Ser 2000, 894:i-xii. I-253.

2. Ogden CL, Carroll MD, Curtin LR, McDowell MA, Tabak CJ, Flegal KM: Prevalence of overweight and obesity in the United States, 1999-2004. Jama 2006, 295:I549-I555.

3. Zimmermann MB, Hess SY, Hurrell RF: A national study of the prevalence of overweight and obesity in 6-12 y-old Swiss children: body mass index, body-weight perceptions and goals. Eur J Clin Nutr 2000, 54:568-572.

4. Sundblom E, Petzold M, Rasmussen F, Callmer E, Lissner L: Childhood overweight and obesity prevalences levelling off in 
Stockholm but socioeconomic differences persist. Int ] Obes (Lond) 2008, 32:1525-1530.

5. Zahner L, Muehlbauer T, Schmid M, Meyer U, Puder JJ, Kriemler S: Association of sports club participation with fitness and fatness in children. Med Sci Sports Exerc 2009, 41:344-350.

6. Lasserre AM, Chiolero A, Cachat F, Paccaud F, Bovet P: Overweight in Swiss children and associations with children's and parents' characteristics. Obesity (Silver Spring) 2007, 15:2912-2919.

7. Freedman DS, Khan LK, Serdula MK, Dietz WH, Srinivasan SR, Berenson GS: The relation of childhood BMI to adult adiposity: the Bogalusa Heart Study. Pediatrics 2005, I I5:22-27.

8. Nader PR, O'Brien M, Houts R, Bradley R, Belsky J, Crosnoe R, Friedman $S$, Mei Z, Susman EJ: Identifying risk for obesity in early childhood. Pediatrics 2006, I I 8:e594-60I.

9. Guo SS, Roche AF, Chumlea WC, Gardner JD, Siervogel RM: The predictive value of childhood body mass index values for overweight at age 35 y. Am J Clin Nutr 1994, 59:810-819.

10. Dietz WH, Robinson TN: Clinical practice. Overweight children and adolescents. N EnglJ Med 2005, 352:2100-2109.

II. Poirier P, Giles TD, Bray GA, Hong Y, Stern JS, Pi-Sunyer FX, Eckel $\mathrm{RH}$ : Obesity and cardiovascular disease: pathophysiology, evaluation, and effect of weight loss: an update of the 1997 American Heart Association Scientific Statement on Obesity and Heart Disease from the Obesity Committee of the Council on Nutrition, Physical Activity, and Metabolism. Circulation 2006, II 3:898-918.

12. Speiser PW, Rudolf MC, Anhalt H, Camacho-Hubner C, Chiarelli F, Eliakim A, Freemark M, Gruters A, Hershkovitz E, lughetti L, et al. Childhood obesity. J Clin Endocrinol Metab 2005, 90:I87I-I887.

13. Freedman DS, Dietz WH, Srinivasan SR, Berenson GS: The relation of overweight to cardiovascular risk factors among children and adolescents: the Bogalusa Heart Study. Pediatrics 1999 , 103: I I75-II82.

14. Baker JL, Olsen LW, Sorensen TI: Childhood body-mass index and the risk of coronary heart disease in adulthood. $\mathrm{N} \mathrm{Engl} \mathrm{J}$ Med 2007, 357:2329-2337.

15. Ekelund U, Sardinha LB, Anderssen SA, Harro M, Franks PW, Brage S, Cooper AR, Andersen LB, Riddoch C, Froberg K: Associations between objectively assessed physical activity and indicators of body fatness in 9- to 10-y-old European children: a population-based study from 4 distinct regions in Europe (the European Youth Heart Study). Am J Clin Nutr 2004, 80:584-590.

16. Robinson TN: Reducing children's television viewing to prevent obesity: a randomized controlled trial. JAMA 1999 , 282: $156 \mid-1567$.

17. Reilly JJ, Armstrong J, Dorosty AR, Emmett PM, Ness A, Rogers I, Steer $C$, Sherriff A: Early life risk factors for obesity in childhood: cohort study. Bmj 2005, 330: 1357.

18. Nicklas TA, Yang SJ, Baranowski T, Zakeri I, Berenson G: Eating patterns and obesity in children. The Bogalusa Heart Study. Am J Prev Med 2003, 25:9-16.

19. Jahns L, Siega-Riz AM, Popkin BM: The increasing prevalence of snacking among US children from I 977 to 1996. J Pediatr 200I, 138:493-498.

20. Bowman SA, Gortmaker SL, Ebbeling CB, Pereira MA, Ludwig DS: Effects of fast-food consumption on energy intake and diet quality among children in a national household survey. Pediatrics 2004, II3:112-118.

21. Tomkinson GR, Leger LA, Olds TS, Cazorla G: Secular trends in the performance of children and adolescents (1980-2000): an analysis of 55 studies of the $20 \mathrm{~m}$ shuttle run test in II countries. Sports Med 2003, 33:285-300.

22. Martin M, Dollman J, Norton K, Robertson I: A decrease in the association between the physical activity patterns of Australian parents and their children; 1985-1 997. J Sci Med Sport 2005, 8:7I-76.

23. Andersen $L B$, van Mechelen $W$ : Are children of today less active than before and is their health in danger? What can we do? Scand J Med Sci Sports 2005, 15:268-270.

24. Reilly J, Jackson DM, Montgomery C, Kelly LA, Slater C, Grant S, Paton JY: Total energy expenditure and physical activity in young Scottish children: mixed longitudinal study. Lancet 2004, 363:21I-212

25. Freedson P, Pober D, Janz KF: Calibration of accelerometer output for children. Med Sci Sports Exerc 2005, 37:S523-530.
26. Weiss R, Dziura J, Burgert TS, Tamborlane WV, Taksali SE, Yeckel CW, Allen K, Lopes M, Savoye M, Morrison J, et al.: Obesity and the metabolic syndrome in children and adolescents. N EnglJ Med 2004, 350:2362-2374

27. Andersen LB, Harro M, Sardinha LB, Froberg K, Ekelund U, Brage S, Anderssen SA: Physical activity and clustered cardiovascular risk in children: a cross-sectional study (The European Youth Heart Study). Lancet 2006, 368:299-304.

28. Kriemler S, Manser-Wenger S, Zahner L, Braun-Fahrlander C, Schindler C, Puder J]: Reduced cardiorespiratory fitness, low physical activity and an urban environment are independently associated with increased cardiovascular risk in children. Diabetologia 2008, 5 I: | 1408-I4I5

29. Brage S, Wedderkopp N, Ekelund U, Franks PW, Wareham NJ, Andersen LB, Froberg K: Features of the metabolic syndrome are associated with objectively measured physical activity and fitness in Danish children: the European Youth Heart Study (EYHS). Diabetes Care 2004, 27:2 I4I-2। 48.

30. Summerbell CD, Ashton V, Campbell KJ, Edmunds L, Kelly S, Waters $\mathrm{E}$ : Interventions for treating obesity in children. Cochrane Database Syst Rev 2003:CD001872.

31. Summerbell CD, Waters E, Edmunds LD, Kelly S, Brown T, Campbell $\mathrm{KJ}$ : Interventions for preventing obesity in children. Cochrane Database Syst Rev 2005:CD00187I.

32. Doak CM, Visscher TL, Renders CM, Seidell JC: The prevention of overweight and obesity in children and adolescents: a review of interventions and programmes. Obes Rev 2006, 7: I I I- I36.

33. Kamath CC, Vickers KS, Ehrlich A, McGovern L, Johnson J, Singhal V, Paulo R, Hettinger A, Erwin PJ, Montori VM: Clinical review: behavioral interventions to prevent childhood obesity: a systematic review and metaanalyses of randomized trials. J Clin Endocrinol Metab 2008, 93:4606-46I5.

34. van Sluijs EM, McMinn AM, Griffin SJ: Effectiveness of interventions to promote physical activity in children and adolescents: systematic review of controlled trials. BMJ 2007, 335:703.

35. Danielzik S, Czerwinski-Mast M, Langnase K, Dilba B, Muller MJ: Parental overweight, socioeconomic status and high birth weight are the major determinants of overweight and obesity in 5-7 y-old children: baseline data of the Kiel Obesity Prevention Study (KOPS). Int J Obes Relat Metab Disord 2004, 28: 1494-1502.

36. Booth SL, Sallis JF, Ritenbaugh C, Hill JO, Birch LL, Frank LD, Glanz K, Himmelgreen DA, Mudd M, Popkin BM, et al: Environmental and societal factors affect food choice and physical activity: rationale, influences, and leverage points. Nutr Rev 200I, 59:S21-39. discussion S57-65.

37. Stokols D, Allen J, Bellingham RL: The social ecology of health promotion: implications for research and practice. $\mathrm{Am} J$ Health Promot 1996, 10:247-251.

38. Muller MJ, Danielzik S, Pust S: School- and family-based interventions to prevent overweight in children. Proc Nutr Soc 2005, 64:249-254.

39. Eisenmann JC, Gentile DA, Welk GJ, Callahan R, Strickland S, Walsh $M$, Walsh DA: SWITCH: rationale, design, and implementation of a community, school, and family-based intervention to modify behaviors related to childhood obesity. BMC Public Health 2008, 8:223.

40. Schweizerisches Netzwerk Gesundheitsfördernder Schulen [http://www.gesunde-schulen.ch/html/projektbrowser.html]

4I. Suisse Balance - Bundesamt für Gesundheit [http:w.suissebalce.ch/logicio/pmws/indexDOM.php?client id=suissebal ance\&page id=prokte\&lang iso639=de]

42. Schweizerische Gesellschaft für Ernährung [http:www.sgssn.ch/fuer-schulen/materialien-fuerdeunterrichernaehrungss cheibe-fuer-kinder/unterrichtsvor schlaege.html]

43. Gesundheitsförderung Schweiz [http://www.gesundheitsfoerd erung.ch/pages/Gesundes Koerpergewicht/Tipps Tools/kidzx.php]

44. Bundesamt für Sport BASPO [http://www.children-on-themove.ch/projektliste.php]

45. Schweizerische Gesellschaft für Ernährung [http://www.sgessn.ch/index.php]

46. BASPO BfS: Bundesamt für Sport BASPO. [http:// www.baspo.admin.ch/]. 
47. Lohman TG, Roche AF, Martorell R: Anthropometric Standardization Reference Manual Champaign, IL: Human Kinetics Books; 1988.

48. Slaughter MH, Lohman TG, Boileau RA, Horswill CA, Stillman RJ, Van Loan MD, Bemben DA: Skinfold equations for estimation of body fatness in children and youth. Hum Biol 1988, 60:709-723.

49. Deurenberg P, Pieters JJ, Hautvast JG: The assessment of the body fat percentage by skinfold thickness measurements in childhood and young adolescence. Br J Nutr 1990, 63:293-303.

50. Dezenberg CV, Nagy TR, Gower BA, Johnson R, Goran MI: Predicting body composition from anthropometry in pre-adolescent children. Int J Obes Relat Metab Disord 1999, 23:253-259.

5I. Eisenmann JC, Heelan KA, Welk GJ: Assessing body composition among 3- to 8-year-old children: anthropometry, BIA, and DXA. Obes Res 2004, 12:1633-1640.

52. Schaefer F, Georgi M, Zieger A, Scharer K: Usefulness of bioelectric impedance and skinfold measurements in predicting fatfree mass derived from total body potassium in children. Pediatr Res 1994, 35:617-624.

53. Bioelectrical impedance analysis in body composition measurement: National Institutes of Health Technology Assessment Conference Statement. Am J Clin Nutr 1996, 64:524S-532S.

54. Kriemler S, Puder J, Zahner L, Roth R, Braun-Fahrlander C, Bedogni G: Cross-validation of bioelectrical impedance analysis for the assessment of body composition in a representative sample of 6- to 13-year-old children. Eur J Clin Nutr 2008 in press.

55. Horlick M, Arpadi SM, Bethel J, Wang J, Moye J Jr, Cuff P, Pierson RN $\mathrm{Jr}$, Kotler D: Bioelectrical impedance analysis models for prediction of total body water and fat-free mass in healthy and HIV-infected children and adolescents. Am J Clin Nutr 2002, 76:991-999.

56. Leger LA, Mercier D, Gadoury C, Lambert J: The multistage 20 metre shuttle run test for aerobic fitness. J Sports Sci 1988, 6:93-101.

57. Liu NY-S, Plowman SA, Looney MA: The reliability and validity of the 20-meter shuttle test in American students $12-15$ years old. Res Q Exerc Sport 1992, 63:6.

58. Mahoney C: $20-M S T$ and PWCI 70 validity in non-Caucasian children in the UK. Br J Sports Med 1992, 26:45-47.

59. Boreham CA, Paliczka V], Nichols AK: A comparison of the PWCI70 and 20-MST tests of aerobic fitness in adolescent schoolchildren. J Sports Med Phys Fitness 1990, 30:19-23.

60. van Mechelen W, Hlobil H, Kemper HC: Validation of two running tests as estimates of maximal aerobic power in children. Eur J Appl Physiol Occup Physiol 1 986, 55:503-506.

61. Ahmaidi SB, Varray AL, Savy-Pacaux AM, Prefaut CG: Cardiorespiratory fitness evaluation by the shuttle test in asthmatic subjects during aerobic training. Chest 1993, I03:| |35-|| |4|.

62. Vogt U: Die Motorik 3-bis 6jähriger Kinder: ihre Abhängigkeit vom biologischen Entwicklungsstand und sozialen Umweltfaktoren. Zugl: Diss Berlin-West. Hofmann; 1978.

63. Kunz T: Weniger Unfälle durch Bewegung: mit Bewegungsspielen gegen Unfälle und Gesundheitsschäden bei Kindergartenkindern/Torsten Kunz Schorndorf: Verlag Karl Hofmann; 1993.

64. Kapteyn TS, Bles W, Njiokiktjien CJ, Kodde L, Massen CH, Mol JM: Standardization in platform stabilometry being a part of posturography. Agressologie 1983, 24:321-326.

65. Malina RM, Bouchard C, Bar-Or O: Growth, maturation, and physical activity 2nd edition. Champaign, III.: Human Kinetics Books; 2004.

66. Pate RR, Almeida MJ, Mclver KL, Pfeiffer KA, Dowda M: Validation and calibration of an accelerometer in preschool children. Obesity (Silver Spring) 2006, 14:2000-2006.

67. Zahner L, Puder JJ, Roth R, Schmid M, Guldimann R, Puhse U, Knopfli M, Braun-Fahrlander C, Marti B, Kriemler S: A school-based physical activity program to improve health and fitness in children aged 6-13 years ("Kinder-Sportstudie KISS"): study design of a randomized controlled trial [ISRCTNI5360785]. BMC Public Health 2006, 6: 147.

68. McDonald A, Van Horn L, Slattery M, Hilner J, Bragg C, Caan B, Jacobs D Jr, Liu K, Hubert H, Gernhofer N, et al.: The CARDIA dietary history: development, implementation, and evaluation. J Am Diet Assoc 1991, 91: I104-1112.

69. Morabia A, Bernstein M, Kumanyika S, Sorenson A, Mabiala I, Prodolliet B, Rolfo I, Luong BL: [Development and validation of a semiquantitative food questionnaire based on a population survey]. Soz Praventivmed 1994, 39:345-369.
70. Varni JW, Limbers CA, Burwinkle TM: Parent proxy-report of their children's health-related quality of life: an analysis of 13,878 parents' reliability and validity across age subgroups using the PedsQL 4.0 Generic Core Scales. Health Qual Life Outcomes 2007, 5: $1-10$

7I. Woerner W, Becker A, Friedrich C, Klasen H, Goodman R, Rothenberger A: Normierung und Evaluation der deutschen Elternversion des Strengths and Difficulties Questionnaire (SDQ): Ergebnisse einer repräsentativen Felderhebung. Zeitschrift für Kinder- und Jugendpsychiatrie und Psychotherapie 2002, 30:105-I I 2.

72. Goodman R: The Strengths and Difficulties Questionnaire: A Research Note. Journal of Child Psychology and Psychiatry 1997, 38:58I-586.

73. Ainsworth BE, Jacobs DR Jr, Leon AS: Validity and reliability of self-reported physical activity status: the Lipid Research Clinics questionnaire. Med Sci Sports Exerc 1993, 25:92-98.

74. Werner H, Molinari L, Guyer C, Jenni OG: Agreement rates between actigraphy, diary, and questionnaire for children's sleep patterns. Arch Pediatr Adolesc Med 2008, 162:350-358.

75. Ettrich KU, Ettrich C: Testmanual zum Konzentrations-Handlungsverfahren für Vorschulkinder Göttingen: Hogrefe; 2006.

76. Grob A, Meyer CS, Hagmann-von Arx P: Intelligence and Development Scales (IDS) Bern: Hans Huber; 2009.

77. Hagmann-von Arx P, Meyer CS, Grob A: Assessing intellectual giftedness with the WISC-IV and the IDS. Journal of Psychology 2008, 216:173-180

78. Hagmann-von Arx P, Meyer CS, Grob A: Intelligenz- und Entwicklungsdiagnostik im deutschen Sprachraum. Kindheit und Entwicklung 2008, 17:232-242

79. Campbell MK, Elbourne DR, Altman DG: CONSORT statement: extension to cluster randomised trials. BM/ 2004, 328:702-708.

\section{Pre-publication history}

The pre-publication history for this paper can be accessed here:

http://www.biomedcentral.com/1471-2458/9/94/prepub

Publish with Biomed Central and every scientist can read your work free of charge

"BioMed Central will be the most significant development for disseminating the results of biomedical research in our lifetime. "

Sir Paul Nurse, Cancer Research UK

Your research papers will be:

- available free of charge to the entire biomedical community

- peer reviewed and published immediately upon acceptance

- cited in PubMed and archived on PubMed Central

- yours - you keep the copyright
BiolMedcentral 